\title{
Publisher Correction: Converting microwave and telecom photons with a silicon photonic nanomechanical interface
}

\author{
G. Arnold, M. Wulf, S. Barzanjeh, E. S. Redchenko, A. Rueda (D), W. J. Hease, F. Hassani \& J. M. Fink (D)
}

Correction to: Nature Communications https://doi.org/10.1038/s41467-020-18269-z, published online 8 September 2020.

The original version of this Article contained errors in the author affiliations. J. M. Fink was incorrectly associated with 'Institute for Quantum Science and Technology (IQST), University of Calgary, Calgary, AB, Canada' in the HTML version of the paper.

Additionally, the present address of the author S. Barzanjeh, 'Institute for Quantum Science and Technology (IQST), University of Calgary, Calgary, AB, Canada' was incorrectly assigned as a full affiliation in the HTML version of the paper.

These errors have been corrected in the HTML version of the Article. The PDF was correct at the time of publication.

Published online: 01 October 2020

(c) (i) Open Access This article is licensed under a Creative Commons Attribution 4.0 International License, which permits use, sharing, adaptation, distribution and reproduction in any medium or format, as long as you give appropriate credit to the original author(s) and the source, provide a link to the Creative Commons license, and indicate if changes were made. The images or other third party material in this article are included in the article's Creative Commons license, unless indicated otherwise in a credit line to the material. If material is not included in the article's Creative Commons license and your intended use is not permitted by statutory regulation or exceeds the permitted use, you will need to obtain permission directly from the copyright holder. To view a copy of this license, visit http://creativecommons.org/licenses/by/4.0/.

(c) The Author(s) 2020 